\title{
NÍVEIS DE FITASE EM RAÇÕES PARA SUÍNOS EM FASE DE TERMINAÇÃO
}

\author{
PHYTASE LEVELS IN RATIONS FOR FINISHING PIGS \\ Lozano, A.P. ${ }^{1 *}$, Pacheco, G.D. ${ }^{1}$, Silva, C.A. ${ }^{1}$, Bridi, A.M. ${ }^{1}$, Silva, R.A.M. ${ }^{1}$, Vinokurovas, S.L. ${ }^{1}$, \\ Dalto, D.B. ${ }^{1}$, Tarsitano, M.A. ${ }^{1}$ e Agostini, P.S.
}

1'Departamento de Zootecnia. Universidade Estadual de Londrina. Brasil. *setaarturo@hotmail.com

\section{PALAVRAS CHAVE ADICIONAIS}

Minerais. Ácido fitico. Desempenho. Impacto ambiental.

\section{RESUMO}

O objetivo do experimento foi avaliar os efeitos da inclusão de diferentes níveis de fitase em rações com elevada concentração de ácido fítico, para suínos em fase de terminação sobre o desempenho, características de carcaça e a qualidade de carne. Os tratamentos experimentais foram: ração sem fitase, e rações com 500, 1000 e 1500 UFA (unidades de fitase). As rações foram formuladas com a base de farelo de gérmen de milho desengordurado, farelo de soja e milho grão, sendo isonutrientes e fornecidas ad libitum durante 28 dias pré-abate. Foram avaliadas as características de desempenho, carcaça, qualidade da carne, oxidação lipídica, os níveis séricos de ferro, cálcio e fósforo, e a concentração fecal de cálcio e fósforo. Foram utilizados 32 suínos (Landrace $\mathrm{x}$ Large Withe), 16 machos castrados e 16 fêmeas, com peso médio inicial de 60,3 $\pm 5,32$ $\mathrm{kg}$, alojados individualmente. O delineamento experimental foi em blocos casualizados, em um modelo fatorial $4 \times 2$ ( 4 níveis de fitase e 2 sexos ), onde a unidade experimental foi o animal. Houve melhora $(p<0,05)$ na conversão alimentar para os tratamentos com 1000 e 1500 UFA de fitase e menor consumo de ração $(p<0,05)$ para o grupo tratado com 1500 UFA de fitase em relação ao grupo controle (sem fitase). Para a perda de água no descongelamento o tratamento com 1500 UFA de fitase apresentou piora $(p<0,05)$ no índice em relação ao grupo controle. Foi verificado efeito quadrático $(p<0,05)$ para a quantidade de fósforo nas fezes, sendo o ponto de mínima de 998,24 UFA, e menores concentrações $(p<0,05)$ para os tratamentos com fitase $(500,1000$ e 1500 UFA) em

Recibido: 10-7-09. Aceptado: 12-5-10.

\section{AdDitional KeYWORDS}

Minerals. Phytic acid. Performance. Environmental impact.

relação ao grupo controle. A adição de fitase sob o nível de 1000 UFA é positiva na redução da eliminação do fósforo fecal e na melhora da conversão alimentar, sem efeitos deletérios na qualidade da carne.

\section{SUMMARY}

This experiment was conducted with the aim of evaluate the inclusion of different levels of phytase in the rations with high phytic acid concentration to finishing pigs on performance, carcass characteristics, and meat quality. The experimental treatments were: ration without phytase, and rations with phytase $(500,1000$ and $1500 \mathrm{PPU})$. The rations were isonutritive, based on corn grain, soybean meal, and defatted corn germen meal ingredients and were offered ad libitum during 28 days before the slaughter. Were evaluated the pig performance, carcass characteristic, meat quality, lipidic oxidation and serum profile of iron, calcium an phosphorus and fecal profile of calcium and phosphorus. Thirty two pigs (Landrace $X$ Large Withe), 16 male and 16 female, with $60.3 \pm 5.32 \mathrm{~kg}$ of initial weight, were allocated on individual pens. The experimental design was randomized blocks, using a $4 \times 2$ factorial model (4 levels of phytase and 2 sexes), been each animal considered a replicate. There was a better $(p<0.05)$ feed conversion rate in groups receiving 1000 and 1500 PPU of phytase and a lower consumption of ration $(p<0.05)$ in the group treated with $1500 \mathrm{PPU}$ of phytase than the control group. It was observed a quadratic effect 
$(p<0.05)$ for phosphorus levels in feces, where the best point was 998.24 PPU, and there were lower concentrations $(p<0.05)$ of phosphorus in the feces of treated groups (500, 1000 and 1500 PPU) compared to the control group. The addition of phytase at the level of 1000 PPU is positive to reduce the phosphorus elimination and improve the feed conversion rate, without deleterious effects on meat quality.

\section{INTRODUÇÃO}

A produção de carne suína tem apresentado crescimento numérico e qualitativo embasado em avanços tecnológicos, conceitos de redução de sua capacidade poluente, promoção do bem-estar animal, baixo custo e oferta de produtos seguros e sensorialmente identificados com as exigências do mercado (Corassa et al., 2009).

Neste cenário, algumas tendências como a utilização de enzimas dietéticas, com destaque à fitase, tem representado um instrumento para atender algumas demandas do segmento. A enzima atua no complexo fitato dos grãos, melhorando a disponibilidade do fósforo, de outros minerais, da energia e da proteína, reduzindo a perda fecal destes nutrientes e promovendo incremento na performance e minimização da poluição ambiental(Pointillart, 1991; Cromwell etal., 1995; Gebert et al., 1999a,b).

Todavia, estas funções primárias da fitase contrastam com seu efeito negativo na redução da ação antioxidante que o fitato desenvolve. O complexo fitato é considerado um potente antioxidante natural, efetivo na inibição da oxidação de produtos alimentares (Grafe Eaton, 1990). Neste sentido, a fitase, pela atuação no ácido fítico, poderia indiretamente expor a carne a maiores taxas de oxidação,processo que resulta na formação de compostos tóxicos e piora a qualidade sensorial e a vida de prateleira da carne (Ghiretti et al., 1997).

Este cenário contraditório expõe dois aspectos, a concomitante tendência de ampliação do uso da fitase e a busca pela substituição dos antioxidantes aritificais
(BHT, BHA, etoxiquinna etc.) pelos naturais, destacando, entre outros, o ácido fítico (Harbach et al., 2006; Souza et al., 2008).

Através da utilização do farelo de gérmen de milho desengordurado (FGMD), coproduto da industrialização do milho que apresenta elevada concentração de ácido fítico, Harbach et al. (2006) verificaram que o fornecimento de dietas com alta inclusão de FGMD para suínos em fase de terminação resultou em redução da oxidação lipídica da carne, sem comprometimento do desempenho zootécnico. Por outro lado, experiências com a participação de fitase na dieta de suínos (Gebert et al., 1999a,b) apontaram piora na oxidação da carne, atribuído ao efeito da enzima.

Considerando que as dietas de suínos no Brasil são formuladas a base de ingredientes de origem vegetal, geralmente grãos de cereais, produtos que têm elevados níveis de ácido fítico, compreender a ação da fitase em dietas com alta concentração de ácido fítico sobre as características relacionadas com o desempenho, com o aproveitamento do fósforo e do cálcio dietético, com a qualidade da carcaça e da carne, com destaque aos efeitos sobre sua oxidação, constituem o objetivo deste trabalho.

\section{MATERIAL E MÉTODOS}

O presente experimento foi submetido à avaliação do comitê de ética da Universidade Estadual de Londrina, sendo aprovado para seu desenvolvimento.

Foram utilizados 32 suínos cruzados (Landrace x Large White), sendo 16 machos castrados e 16 fêmeas. A avaliação foi iniciada com os animais apresentando $60,3 \pm 5,32 \mathrm{~kg}$ de peso vivo e idade de 110 dias de idade. Os animais foram alojados individualmente em baias de alvenaria, com piso compacto, com $3 \mathrm{~m}^{2}$ de área.

$\mathrm{O}$ delineamento experimental foi em blocos casualizados (divididos em 4 blocos de acordo com o peso inicial dos animais), em esquema fatorial 4 × 2 (4 níveis de inclusão de fitase e 2 sexos), com 4 repetições por 


\section{FITASE PARA RAÇÕES COM ALTO ÁCIDO FÍTICO}

tratamento, onde cada animal representou uma parcela experimental.

Os tratamentos experimentais consistiram no fornecimento, durante 28 dias, de quatro dietas a base de milho, farelo de soja e farelo de gérmen de milho desengordurado, com inclusão crescente de fitase (NATUPHOS ${ }^{\circledR} 5000$ ), expressa em unidades de fitase (UFA), sendo: ração sem fitase, e rações com 500, 1000 e 1500 UFA. As rações eram isoenergéticas e isoprotéicas, sendo formuladas visando atender as exigências mínimas estabelecidas pelo NRC (1998) para suínos em fase de termi- nação (tabela I).

O fornecimento de água e ração foi ad libitum para todos os tratamentos durante 28 dias. As avaliações de desempenho constaram da mensuração do ganho diário de peso, consumo diário de ração e conversão alimentar.

No $14^{\circ}$ dia de experimento foi realizada a coleta de $20 \mathrm{ml}$ de sangue, via veia jugular, para a obtenção do soro para a determinação da concentração sérica de cálcio, fósforo e ferro, através do uso de kits enzimáticos colorimétricos.

Para a análise da presença de fósforo e

Tabela I. Composição percentual, química e energética das rações experimentais. (Chemical and energy composition (\%) of the experimental diets).

\begin{tabular}{|c|c|c|c|c|}
\hline \multirow[b]{2}{*}{ Ingredientes (\%) } & \multicolumn{4}{|c|}{ Níveis de fitase (unidades de fitase, UFA) } \\
\hline & 0 & 500 & 1000 & 1500 \\
\hline Farelo de gérmen de milho desengordurado & 40,00 & 40,00 & 40,00 & 40,00 \\
\hline Milho & 38,46 & 38,25 & 38,04 & 37,83 \\
\hline Farelo de soja & 15,80 & 15,84 & 15,88 & 15,92 \\
\hline Óleo de soja & 3,19 & 3,26 & 3,33 & 3,40 \\
\hline Núcleo único suino ${ }^{2}$ & 2,00 & 2,00 & 2,00 & 2,00 \\
\hline Sal & 0,30 & 0,30 & 0,30 & 0,30 \\
\hline Fosfato & 0,19 & 0,19 & 0,19 & 0,19 \\
\hline L-Lisina-HCL & 0,06 & 0,06 & 0,06 & 0,06 \\
\hline Fitase & & 0,10 & 0,20 & 0,30 \\
\hline Total & 100 & 100 & 100 & 100 \\
\hline \multicolumn{5}{|l|}{ Valores calculados } \\
\hline Cálcio (\%) & 0,740 & 0,740 & 0,740 & 0,740 \\
\hline Energia digestível (Kcal/kg) & 3.338 & 3.338 & 3.338 & 3.338 \\
\hline Energia metabolizável (Kcal/kg) & 3.142 & 3.142 & 3.142 & 3.142 \\
\hline Fósforo disponível (\%) & 0,250 & 0,250 & 0,250 & 0,250 \\
\hline Fósforo total (\%) & 0,582 & 0,582 & 0,582 & 0,582 \\
\hline Lisina (\%) & 0,750 & 0,750 & 0,750 & 0,750 \\
\hline Metionina (\%) & 0,251 & 0,251 & 0,251 & 0,251 \\
\hline Proteína bruta (\%) & 15,5 & 15,5 & 15,5 & 15,5 \\
\hline Sódio (\%) & 0,144 & 0,144 & 0,144 & 0,144 \\
\hline Acido fitico ${ }^{4}(\%)$ & 4,84 & 4,81 & 4,85 & 4,85 \\
\hline
\end{tabular}

${ }^{1}$ Composição do núcleo único suínos por kg de produto: vit. A, 239.000 Ul; vit.B12, 538 mcg; vit.D3, 66.000 Ul; vit.E, $517 \mathrm{mg}$; vit.K3, $60 \mathrm{mg}$; ácido fólico, $32 \mathrm{mg}$; ácido pantotênico, $254 \mathrm{mg}$; biotina, $1,1 \mathrm{mg}$; niacina, $422 \mathrm{mg}$; piridoxina, $41 \mathrm{mg}$; riboflavina, $90 \mathrm{mg}$; tiamina, $33 \mathrm{mg}$; colina, $4 \mathrm{~g}$; promotor de crescimento, 2595 mg; Ca, 231 g; Co, 5,5 mg; Cu, 5000 mg; Fe, 2760 mg; F, 881 mg; P, 59 g; I, 43 mg; Mn, 1,310 mg; Se, $8,46 \mathrm{mg} ; \mathrm{Na}, 50 \mathrm{~g} ; \mathrm{Zn}, 3720 \mathrm{mg} ;{ }^{2}$ Determinado pela técnica descrita por Chen et al. (1956) e por Thompson e Erdam (1982) 
cálcio nas fezes foi realizada a técnica de coleta parcial de fezes utilizando óxido crômico $(0,3 \%)$ como marcador fecal, quando os animais atingiram o peso vivo médio de $76,25 \pm 8,18 \mathrm{~kg}$. As rações marcadas foram oferecidas aos suínos e após três dias de consumo as fezes foram coletadas e armazenadas em sacos plásticos e mantidas em temperatura de congelamento. Posteriormente, as fezes foram descongeladas, secas em estufa de ventilação forçada a $60^{\circ}$ $\mathrm{C}$ por três dias e trituradas. Em seguida foram encaminhadas para análise de acordo com a técnica proposta por Malavolta et al. (1992) e Silva (1999).

Em relação ao manejo pré-abate, a ração foi retirada 12 horas antes do embarque, permanecendo os animais sob dieta hídrica até o abate.

Previamente ao abate procedeu-se a insensibilização elétrica dos animais (350 volts e 1,3 ampéres, durante 3 segundos), sendo utilizado um equipamento da marca Petrovina ${ }^{\circledR}$ IS 2000 com dois eletrodos. A sangria foi realizada através do corte dos grandes vasos do pescoço. Após o abate, escaldagem e evisceração, as carcaças foram divididas ao meio longitudinalmente e resfriadas à temperatura de $2 \pm 1^{\circ} \mathrm{C}$, por 24 horas, na câmara de resfriamento.

As carcaças foram avaliadas individualmente de acordo com as metodologias citadas por Bridi e Silva (2007), onde foram obtidos os dados de espessura de toucinho (ET), profundidade do músculo Longissimus dorsi (PM), área de olho de lombo (AOL), peso da carcaça quente (PCQ), peso da carcaça fria $(\mathrm{PCF})$ e rendimento de carcaça (RC). O peso da carcaça quente e da carcaça fria foram utilizados para determinação de porcentagem de perda da carcaça no resfriamento. A partir dos valores dessas medidas, estimou-se o rendimento e a quantidade de carne na carcaça (RCC e QCC), de acordo com a metodologia estabelecida por Guidoni (2000).

$\mathrm{O} \mathrm{pH}$ da carne foi medido no músculo Longissimus dorsi, na altura da última

Tabela II. Médias e desvios-padrão observados do ganho de peso total (GPT), ganho diário de peso $(G D P)$, consumo total de ração (CTR), consumo diário de ração (CDR) e conversão alimentar (CA) de suínos, de acordo com o nível de inclusão de fitase na ração e o sexo. (Mean and standard deviation of weight gain (GPT), daily weight gain (GDP), feed consumption (CTR), daily feed consumption (CDR) and feed conversion ratio $(C A)$ related to inclusion levels of phytase in the diet and pig sex).

\begin{tabular}{lccccc}
\hline Tratamentos & GPT $(\mathrm{kg})$ & GDP $(\mathrm{kg})$ & CTR $(\mathrm{kg})$ & CDR $(\mathrm{kg})$ & CA \\
\hline Níveis de fitase & & & & & \\
$\quad$ O UFA & $26,99 \pm 3,4$ & $0,93 \pm 0,1$ & $76,27 \pm 4,4$ & $2,63 \pm 0,1$ & $2,85 \pm 0,2$ \\
500 UFA & $27,28 \pm 5,5$ & $0,94 \pm 0,1$ & $75,63 \pm 9,4$ & $2,60 \pm 0,3$ & $2,82 \pm 0,3$ \\
1000 UFA & $28,02 \pm 4,6$ & $0,96 \pm 0,1$ & $73,83 \pm 9,4$ & $2,54 \pm 0,3$ & $2,65 \pm 0,1^{*}$ \\
$\quad 1500$ UFA & $26,78 \pm 6,1$ & $0,92 \pm 0,2$ & $71,46 \pm 11,2^{*}$ & $2,46 \pm 0,3^{*}$ & $2,72 \pm 0,3^{*}$ \\
Sexos & & & & & \\
$\quad$ Macho & $29,23 \pm 3,9$ & $1,00 \pm 0,1$ & $78,90 \pm 4,9$ & $2,72 \pm 0,1$ & $2,73 \pm 0,2$ \\
Fêmea & $25,31 \pm 4,9$ & $0,87 \pm 0,1$ & $69,70 \pm 9,4$ & $2,40 \pm 0,3$ & $2,79 \pm 0,2$ \\
& $\mathrm{NS}$ & $\mathrm{NS}$ & $\mathrm{NS}$ & $\mathrm{NS}$ & $\mathrm{NS}$ \\
\hline CV (\%) & 12,53 & 12,58 & 8,72 & 8,76 & 6,99 \\
Teste de Dunnnet & - & - & 0,05 & 0,05 & 0,05 \\
Regressão & - & - & - & - & - \\
\hline
\end{tabular}

CV: Coeficiente de variação; *Valor diferente $(p<0,05)$ em relação à testemunha pelo teste de Dunnet.

Archivos de zootecnia vol. 60, núm. 232, p. 842. 


\section{FITASE PARA RAÇÕES COM ALTO ÁCIDO FÍTICO}

costela, aos 45 minutos após o abate (pH inicial) e após 24 horas de resfriamento a aproximadamente $2 \pm 1^{\circ} \mathrm{C}$ ( $\mathrm{pH}$ final).

Vinte e quatro horas após o resfriamento, foi retirada de cada meia carcaça esquerda uma amostra do músculo Longissimus dorsi de aproximadamente $20 \mathrm{~cm}$ de comprimento, que foi submetido à extração da gordura adjacente e subdivididas transversalmente em 5 amostras de aproximadamente 2,5 cm de espessura cada para as análises de cor, marmoreio, perda de água por gotejamento, perda de água no descongelamento e na cocção e a força de cisalhamento. Uma amostra foi utilizada para a avaliação da oxidação lipídica.

Para a análise de cor, as amostras foram analisadas 24 horas após o abate, utilizando o colorímetro portátil Minolta ${ }^{\circledR} \mathrm{CR} 10, \mathrm{com}$ esfera de integração e ângulo devisão de $8^{\circ}$, ou seja, iluminação $\mathrm{d} / 8$ e iluminate $\mathrm{C}$. Os componentes L* (luminosidade), a* (com- ponente vermelho-verde) e b* (componente amarelo-azul) foram expressos no sistema de cor CIELAB. Com esses valores calculouse o ângulo de tonalidade $\left(\mathrm{h}^{*}\right)$ pela equação $\mathrm{h}^{*}=\tan -1\left(\mathrm{~b}^{*} / \mathrm{a}^{*}\right)$, e o índice de saturação $\left(c^{*}\right)$ a partir da equação $c^{*}=\left(a^{* 2}+b^{* 2}\right)^{0,5}$. Estas mesmas amostras também foram avaliadas subjetivamente para marmoreio, utilizando-se padrões fotográficos (National Pork Producers Council, 1991), onde foram atribuídas notas de 1 a 5 (1= traços de marmoreio e 5= marmoreio abundante).

A perda de água por gotejamento foi avaliada segundo Boccard et al. (1981). A perda de água no descongelamento e após o cozimento foram determinadas segundo a técnica descrita por Bridi e Silva (2007).

A força de cisalhamento foi tomada perpendicularmente à orientação das fibras musculares com a lâmina Warner-Bratzler adaptada no texturômetro Stable Mycro Systems TA-XT2i (Bouton et al., 1971). As

Tabela III. Médias e desvios-padrão observados para fósforo nas fezes (FOSFZ), cálcio nas fezes (CAFZ), cálcio no sangue (CASG), fósforo no sangue (FOSG) e ferro no sangue (FESG) de suínos, de acordo com o nível de inclusão de fitase na ração e do sexo. (Mean and standard deviation for fecal phosphorus (FOSFZ) and calcium (CAFZ), and seric calcium (CASG), phosphorus (FOSG) and iron (FESG), in relation to inclusion levels of phytase in the diet and pig sex).

\begin{tabular}{|c|c|c|c|c|c|}
\hline Tratamentos & $\begin{array}{c}\text { FOSFZ } \\
(\mathrm{mg} / 100 \mathrm{~g})\end{array}$ & $\begin{array}{c}\text { CAFZ } \\
(\mathrm{mg} / 100 \mathrm{~g})\end{array}$ & $\begin{array}{l}\text { CASG } \\
(\mathrm{mg} / \mathrm{ml})\end{array}$ & $\begin{array}{c}\text { FOSG } \\
(\mathrm{mg} / \mathrm{ml})\end{array}$ & $\begin{array}{l}\text { FESG } \\
(\mathrm{mg} / \mathrm{ml})\end{array}$ \\
\hline \multicolumn{6}{|l|}{ Níveis de fitase } \\
\hline 0 UFA & $2,06 \pm 0,7$ & $1,20 \pm 0,2$ & $11,95 \pm 0,6$ & $9,25 \pm 0,6$ & $166,80 \pm 16,3$ \\
\hline 500 UFA & $1,26 \pm 0,3^{*}$ & $0,95 \pm 0,3^{*}$ & $11,40 \pm 0,3^{*}$ & $8,87 \pm 0,4$ & $177,00 \pm 43,4$ \\
\hline 1000 UFA & $1,42 \pm 0,5^{\star}$ & $1,11 \pm 0,4$ & $11,82 \pm 0,5$ & $8,97 \pm 0,3$ & $163,80 \pm 50,5$ \\
\hline 1500 UFA & $1,38 \pm 0,5^{*}$ & $1,11 \pm 0,3$ & $11,35 \pm 0,5^{\star}$ & $8,65 \pm 0,4^{*}$ & $111,90 \pm 50,5^{*}$ \\
\hline \multicolumn{6}{|l|}{ Sexo } \\
\hline Macho & $1,58 \pm 0,6$ & $1,19 \pm 0,2$ & $11,82 \pm 0,5$ & $8,97 \pm 0,3$ & $155,40 \pm 42,7$ \\
\hline \multirow[t]{2}{*}{ Fêmea } & $1,48 \pm 0,5$ & $1,01 \pm 0,3$ & $11,43 \pm 0,5$ & $8,90 \pm 0,6$ & $154,35 \pm 52,4$ \\
\hline & NS & NS & NS & NS & NS \\
\hline CV $(\%)$ & 25,19 & 18,18 & 4,62 & 5,84 & 29,94 \\
\hline Teste de Dunnnet & 0,05 & 0,05 & 0,05 & 0,05 & 0,05 \\
\hline Regressão & Quadrático ${ }^{1}$ & - & - & - & - \\
\hline
\end{tabular}

CV: Coeficiente de variação; ${ }^{1} Y=2,00633-0,00151733 X+0,00000076 X^{2} ;$ *Valor diferente $(p<0,05)$ em relação à testemunha pelo teste de Dunnet. 
velocidades utilizadas para a secção do músculo foram de $5 \mathrm{~mm} / \mathrm{s}$ no pré e pós teste e de $2 \mathrm{~mm} / \mathrm{s}$ no teste.

A oxidação lipídica foi determinada após 30 dias do abate, no músculo Longissimus dorsi, pelo método do ácido 2-tiobarbitúrico, conforme procedimento descrito por Tarladgis et al. (1964) e modificado por Crackel et al.(1988).

Os dados foram submetidos à análise de variância com derivação de polinômios (regressão) utilizando-se o programa estatístico SAEG (UFV, 1997). Para a avaliação comparativa dos níveis de fitase foi aplicado o teste de Dunnet (Sampaio, 1998).

\section{RESULTADOSEDISCUSSÃO}

Os resultados do desempenho zootécnico (tabela II), não indicam efeito de regressão, diferença entre sexos ou interação dos fatores $(p>0,05)$. No entanto, para o consumo total e diário de ração e para a conversão alimentar, o nível mais elevado de fitase (1500 UFA) resultou em menores consumos de ração $(\mathrm{p}<0,05)$ e para os níveis de 1000 e 1500 UFA a conversão apresentouse melhor comparada com a ração testemunha $(\mathrm{p}<0,05)$.

Os resultados para o consumo diário de ração apresentaram-se semelhantes aos observados por Ludke et al. (2002a), que encontraram um consumo diário de ração de $2381 ; 2345$ e 2320 g, para níveis de $0 ; 750$ e 1000 UFA, respectivamente, não demonstrando diferenças entre os tratamentos. Harper et al. (1997), suplementando suínos em crescimento/terminação com 250 e 500 UFA, e Souza et al. (2008), alimentando suínos em terminação com 500 UF, com e sem suplemento micromineral-vitamínico, também não verificaram diferenças para o desempenho entre os tratamentos, contrastando com os menores consumos de ração e melhores conversões observados neste trabalho para os níveis de 1000 e 1500 UFA.

Para a conversão alimentar os resulta-

Tabela IV. Médias e desvios-padrão observados no peso médio de abate (PMA), peso de carcaça quente (PCQ), rendimento de carcaça $(R C)$, porcentagem de perda de peso da carcaça no resfriamento (PCR) de suínos, de acordo com o nível de inclusão de fitase na ração e do sexo. (Mean and standard deviation of slaughter weight (PMA), hot carcass weight (PCQ), carcass yield (RC) and percentage of cold carcase losses (PCR) related to inclusion levels of phytase in the diet and pig sex).

\begin{tabular}{lcccc}
\hline Tratamentos & PMA $(\mathrm{kg})$ & $\mathrm{PCQ}(\mathrm{kg})$ & $\mathrm{RC}(\%)$ & $\mathrm{PCR}(\%)$ \\
\hline Níveis de fitase & & & & \\
0 UFA & $87,37 \pm 4,3$ & $65,96 \pm 3,5$ & $75,49 \pm 1,6$ & $2,66 \pm 0,2$ \\
500 UFA & $87,13 \pm 7,4$ & $66,14 \pm 5,7$ & $75,94 \pm 2,2$ & $2,69 \pm 0,2$ \\
1000 UFA & $88,46 \pm 6,5$ & $67,11 \pm 5,4$ & $75,84 \pm 1,6$ & $2,66 \pm 0,3$ \\
1500 UFA & $87,21 \pm 11,5$ & $65,77 \pm 9,2$ & $75,40 \pm 2,7$ & $2,67 \pm 0,3$ \\
Sexos & $91,18 \pm 6,7$ & $69,12 \pm 5,9$ & $75,76 \pm 2,3$ & $2,64 \pm 0,3$ \\
$\quad$ Macho & $83,90 \pm 6,6$ & $63,37 \pm 4,7$ & $75,57 \pm 1,7$ & $2,69 \pm 0,2$ \\
Fêmea & $\mathrm{NS}$ & $\mathrm{NS}$ & $\mathrm{NS}$ & $\mathrm{NS}$ \\
& 6,15 & 6,87 & 1,64 & 4,23 \\
\hline CV (\%) & - & - & - & - \\
Teste de Dunnnet & - & - & - & - \\
Regressão & & &
\end{tabular}

CV: Coeficiente de variação.

Archivos de zootecnia vol. 60, núm. 232, p. 844. 


\section{FITASE PARA RAÇÕES COM ALTO ÁCIDO FÍTICO}

dos foram semelhantes aos obtidos por Ludke et al. (2002b) que observaram melhora do parâmetro $(\mathrm{p}<0,05)$ de acordo com a inclusão crescente de fitase $(0,300,600 \mathrm{e}$ 900 UFA) às dietas. Quanto ao ganho de peso, contrário aos resultados de Biehl e Baker (1996), que usaram 1200 UFA/kg para uma dieta à base de milho e farelo de soja, a inclusão de fitase não determinou diferença entre os tratamentos.

As rações experimentais apresentavam níveis de ácido fítico próximos a 5\% (tabela I), valores estes superiores aos níveis encontrados em rações formuladas à base de milho e farelo de soja. Neste sentido, a participação da fitase sob concentrações mais elevadas nas rações podem ter sido efetivamente a causa da melhor conversão alimentar obtida, devido ao aproveitamento mais eficiente do fósforo, de outros minerais e de proteína e aminoácidos. Beers e Jongbloed (1992), utilizando 1450 UF/kg de ração, para leitões, observaram uma melhora de $4,4 \%$ na conversão alimentar atribuída aos efeitos extra-fosfóricos da enzima, efeito este representado pelo aumento da digestibilidade de proteínas e aminoácidos da dieta.

Quanto à quantidade de fósforo, cálcio e ferro no sangue e de cálcio e fósforo nas fezes (tabela III), observou-se que o principal resultado foi determinado para o parâmetro fósforo nas fezes, com efeito quadrático com ponto de mínima para 998,24 UFA. A equação aponta melhor aproveitamento do fósforo da dieta à medida que aumentou a concentração de fitase. Todavia, pode-se atribuir que as demandas diárias dos animais para o mineral tenham sido atendidas até o nível de 998,24 UFA, com aumento da excreção do fósforo após o ponto de mínima. Moreira et al. (2004), trabalhando com suínos em terminação, também encontraram efeito quadrático

Tabela $\boldsymbol{V}$. Médias e desvios-padrão observados para profundidade de músculo (PM), área de olho de lombo (AOL), quantidade de carne na carcaça resfriada (QCR), rendimento de carne (RCN), e espessura de toucinho (ET) de suínos, de acordo com o nível de inclusão de fitase na ração e do sexo. (Means and standard deviations observed for muscle depth (PM), loin eye area (AOL), amount of meat in chilled carcass (QCR), meat yield (RCN), and back fat thickness (ET) from pigs, according to the level of inclusion of phytase in the diet, and sex).

\begin{tabular}{lccccc}
\hline Tratamentos & PM $(\mathrm{mm})$ & AOL $(\mathrm{cm})$ & QCR $(\mathrm{kg})$ & $\mathrm{RCN}(\%)$ & $\mathrm{ET}(\mathrm{mm})$ \\
\hline Níveis de fitase (UFA) & & & & & \\
$\quad$ O UFA & $58,62 \pm 4,1$ & $37,33 \pm 3,1$ & $40,67 \pm 1,4$ & $60,07 \pm 1,7$ & $9,98 \pm 3,0$ \\
500 UFA & $62,54 \pm 3,8^{*}$ & $39,33 \pm 6,1$ & $41,03 \pm 3,0$ & $60,50 \pm 1,9$ & $9,92 \pm 3,2$ \\
1000 UFA & $62,15 \pm 6,4^{*}$ & $39,49 \pm 4,7$ & $41,52 \pm 2,8$ & $60,46 \pm 2,5$ & $9,90 \pm 3,9$ \\
1500 UFA & $60,00 \pm 5,0$ & $36,83 \pm 5,0$ & $40,22 \pm 3,3$ & $59,69 \pm 2,5$ & $10,88 \pm 4,7$ \\
& $\mathrm{NS}$ & $\mathrm{NS}$ & $\mathrm{NS}$ & $\mathrm{NS}$ & $\mathrm{NS}$ \\
Sexo & & & & & \\
$\quad$ Macho & $61,11 \pm 5,3$ & $38,07 \pm 5,8$ & $41,63 \pm 2,6$ & $59,30 \pm 2,4$ & $11,74 \pm 4,0$ \\
Fêmea & $60,55 \pm 4,9$ & $38,42 \pm 3,7$ & $40,09 \pm 2,5$ & $61,03 \pm 1,3$ & $8,60 \pm 2,4$ \\
& $\mathrm{NS}$ & $\mathrm{NS}$ & $\mathrm{NS}$ & $\mathrm{NS}$ & $\mathrm{NS}$ \\
\hline CV (\%) & 8,43 & 12,84 & 5,23 & 2,53 & 26,15 \\
Teste de Dunnnet & 0,05 & - & - & - & - \\
Regressão & - & - & - & - & -
\end{tabular}

CV: Coeficiente de variação; *Valor diferente $(p<0,05)$ em relação à testemunha pelo teste de Dunnet. 
$(p<0,05)$ entre os níveis de fósforo nas fezes e os níveis crescentes de fitase $(221,83$; 182,$07 ; 211,65$ e 229,09 mg para 253; 759; 1265 e 1748 UFA, respectivamente). Este resultado foi semelhante aos obtidos por Cromwell et al. (1995) e Figueirêdo et al. (2000), que observaram redução da excreção de fósforo com o uso de fitase. Ao se comparar a presença de fósforo nas fezes dos grupos que receberam fitase com o grupo controle, houve diferença $(\mathrm{p}<0,05)$ para todos os níveis testados.

Quanto ao nível de cálcio nas fezes, os resultados mostraram menor perda do mineral para o nível de 500 UFA, sugerindo que sob esta concentração a disponibilização do mineral atendeu as demandas dos animais. Possivelmente, sob níveis mais elevados haja maior liberação de cálcio, que, sob excesso, resulta em maior excreção do mineral. Estes resultados diferem de Mroz et al. (1994) e Liu et al. (1997), que demonstraram melhor aproveitamento do cálcio em suínos tratados com dietas com diferentes níveis de fitase.
Para os valores de cálcio, fósforo e ferro no sangue foi observado, na comparação com o grupo controle, diferenças significativas para os níveis de 500 e 1500 UFA para o cálcio sérico, e diferença para o fósforo e o ferro sérico para o nível de 1500 UFA. Estes resultados são contrários aos obtidos por Moreira et al. (2003), que verificaram que os níveis de fósforo sérico não foram alterados pelo uso da fitase dietética (253; $759 ; 1265$ e 1748 UFA), atribuindo o refluxo do mineral para o trato gastrintestinal e ao aparelho urinário a regulação de sua concentração no sangue.

Para o ferro sérico, Almeida et al. (2007), trabalhando com fêmeas alimentadas com dietas contendo 500 UFA/kg de ração, com e sem suplemento vitamínico-mineral, também não observaram diferenças $(\mathrm{p}>0,05)$ para o mineral.

Para o peso ao abate e para as características de carcaça os resultados demonstrados na tabela IV mostram que não houve efeito de regressão, diferenças ( $p>0,05)$ entre os sexos e interação entre os fatores. Nenhuma

Tabela VI. Médias e desvios-padrão observados sobre os valores de cor ( $\left.a^{*}, b^{*}, L^{*}, c^{*}, h^{*}\right)$ do músculo Longissimus dorsi de suínos, de acordo com os níveis de fitase na ração e o sexo. (Mean and standard deviation of color traits $\left(a^{*}, b^{*}, L^{*}, c^{*}, h^{*}\right)$ in Longissimus dorsi muscle related to inclusion levels of phytase in the diet and pig sex).

\begin{tabular}{lccccc}
\hline Tratamentos & $\mathrm{a}^{*}$ & $\mathrm{~b}^{*}$ & $\mathrm{~L}^{*}$ & $\mathrm{C}^{*}$ & $\mathrm{~h}^{*}\left({ }^{\circ}\right)$ \\
\hline Níveis de fitase & & & & & \\
$\quad$ 0 UFA & $3,91 \pm 1,9$ & $9,23 \pm 2,1$ & $54,42 \pm 3,1$ & $10,10 \pm 2,6$ & $67,95 \pm 7,4$ \\
$\quad$ 500 UFA & $4,59 \pm 1,8$ & $9,72 \pm 1,1$ & $54,43 \pm 4,0$ & $10,83 \pm 1,6$ & $65,41 \pm 7,1$ \\
$\quad$ 1000 UFA & $2,81 \pm 1,1^{\dagger}$ & $8,86 \pm 1,2$ & $55,75 \pm 3,8$ & $9,30 \pm 1,4$ & $73,02 \pm 6,4^{\dagger}$ \\
$\quad$ 1500 UFA & $3,46 \pm 1,3^{\dagger}$ & $9,10 \pm 0,6$ & $55,79 \pm 3,9$ & $9,70 \pm 0,9$ & $69,70 \pm 6,9$ \\
Sexos & $3,64 \pm 1,8$ & $9,42 \pm 1,7$ & $56,36 \pm 3,8$ & $10,19 \pm 2,1$ & $69,96 \pm 8,2$ \\
$\quad$ Macho & $3,70 \pm 1,5$ & $9,04 \pm 0,9$ & $53,83 \pm 3,0$ & $9,84 \pm 1,3$ & $68,08 \pm 6,1$ \\
Fêmea & NS & NS & NS & NS & NS \\
& 42,92 & 14,07 & 5,47 & 16,75 & 10,04 \\
\hline CV (\%) & 0,05 & - & - & - & 0,05 \\
Teste de Dunnnet & - & - & - & - & - \\
Regressão & & & & &
\end{tabular}

CV: Coeficiente de variação; ${ }^{\dagger}$ Valor diferente $(p<0,05)$ em relação à testemunha pelo teste de Dunnet. $a^{*}$ Saturação; b* tonlidade; L* Luminosidade; $h^{*}$ Tonalidade da cor; c* Saturação. 
FITASE PARA RAÇÕES COM ALTO ÁCIDO FÍTICO

Tabela VII. Médias e desvios-padrão observados para pHinicial (pHi), pHfinal (pHf), perda de liquido no descongelamento (PLD), perda de liquido no cozimento (PLC) e perda de água por gotejamento (DRIP) de suínos, de acordo com o nível de inclusão de fitase na ração e do sexo. (Mean and standard deviation of initial $(\mathrm{pHi})$ and final $\mathrm{pH}(\mathrm{pHf})$, defrosting loss (PLD), cooking loss (PLC) and drip loss (DRIP) related to inclusion levels of phytase in the diet and pig sex).

\begin{tabular}{|c|c|c|c|c|c|}
\hline Tratamentos & $\mathrm{pHi}$ & $\mathrm{pHf}$ & PLD (\%) & PLC (\%) & DRIP (\%) \\
\hline \multicolumn{6}{|l|}{ Níveis de fitase } \\
\hline 0 UFA & $6,43 \pm 0,6$ & $5,71 \pm 0,2$ & $6,30 \pm 1,8$ & $39,90 \pm 3,8$ & $6,57 \pm 3,9$ \\
\hline 500 UFA & $6,27 \pm 0,4$ & $5,54 \pm 0,1^{*}$ & $7,77 \pm 3,0$ & $39,47 \pm 1,0$ & $7,40 \pm 2,9$ \\
\hline 1000 UFA & $6,42 \pm 0,2$ & $5,69 \pm 0,2$ & $7,08 \pm 2,9$ & $38,54 \pm 2,7$ & $7,56 \pm 2,5$ \\
\hline 1500 UFA & $6,26 \pm 0,4$ & $5,67 \pm 0,3$ & $8,23 \pm 1,9^{*}$ & $42,34 \pm 8,0$ & $7,12 \pm 4,0$ \\
\hline \multicolumn{6}{|l|}{ Sexos } \\
\hline Macho & $6,26 \pm 0,5$ & $5,64 \pm 0,3$ & $7,54 \pm 2,7$ & $39,07 \pm 2,9$ & $7,51 \pm 2,9$ \\
\hline \multirow[t]{2}{*}{ Fêmea } & $6,43 \pm 0,3$ & $5,66 \pm 0,1$ & $7,15 \pm 2,2$ & $41,06 \pm 5,9$ & $6,80 \pm 3,7$ \\
\hline & NS & NS & NS & NS & NS \\
\hline CV (\%) & 7,17 & 4,58 & 24,54 & 11,87 & 39,00 \\
\hline Teste de Dunnnet & - & 0,05 & - & - & 0,05 \\
\hline Regressão & - & - & - & - & - \\
\hline
\end{tabular}

CV: Coeficiente de variação; *Valor diferente $(p<0,05)$ em relação à testemunha pelo teste de Dunnet.

diferença em relação ao grupo controle foi identificada.

Os resultados obtidos foram contrários aos observados por Harper et al. (1997), que encontraram aumento linear no peso médio de abate dos animais em fase de crescimentoterminação alimentados com dietas com a adição de fitase nos níveis de 0,167 e 333 UFA/kg. Todavia, Corassa et al. (2009) trabalhando com níveis crescentes de fitase (0; 500 e 750 UF), não encontraram melhoras no peso de abate e no peso da carcaça quente, verificando somente resultados superiores $(p<0,05)$ para o rendimento carcaça (500 UF).

Outros estudos com suínos (Ludke et al., 2002c; Santos et al., 2008) também não observaram melhora nos parâmetros de carcaça com a inclusão da fitase na dieta.

Os valores de profundidade de músculo, espessura de toucinho, quantidade de carne na carcaça resfriada, rendimento de carne e espessura de toucinho são apresentados na tabela $V$.
Não foi observado efeito de regressão para as variáveis, vantagens para algum sexo ou interação dos fatores. Com relação à profundidade do músculo lombar os grupos que receberam 500 e 1000 UFA foram melhores em relação ao grupo alimentado com ração isenta de fitase, contrariando Peter et al. (2001), que não encontraram efeito da fitase sobre as características.

Segundo Peter et al. (2001), os efeitos da administração de fitase (300 e 500 UFA) em rações com baixo nível de fósforo $(0,32 \mathrm{ver}$ sus $0,12 \%$ ) para suínos em fase final de engorda não influenciou os parâmetros de carcaça.

Os resultados referentes aos valores de cor do músculo Longissimus dorsi (tabela VI) apontam também ausência de efeito de regressão, ou efeitos do fator sexo e de interação ( $p>0,05)$. Souza et al. (2008), trabalhando com suínos em terminação com inclusão de 500 UF e com ou sem suplemento de micro-minerais e vitamínicos, também não verificaram diferenças para cor da car- 
ne. Contudo, quando utilizada a comparação dos níveis de fitase com o grupo controle (sem fitase), para os parâmetros componente vermelho-verde ( $a^{*}$ ) e ângulo de tonalidade, observou-se diferença $(p<0,05)$ para os grupos que receberam 1000 e 1500 UFA, ou seja, o músculo Longissimus dorsi apresentou coloração mais avermelhada em relação ao grupo tratado com ração sem fitase. Para o parâmetro ângulo de tonalidade $\left(h^{*}\right)$, houve diferença $(\mathrm{p}<0,05)$ para o grupo tratado com 1000 UFA, comparado com o grupo controle, apontando que o músculo apresentou uma maior absorção de energia radiante de cores em vários comprimentos de onda.

A fitase tem a capacidade de liberar o fósforo fitico presente nos cereais e outros minerais seqüestrados, com destaque ao ferro, potente catalizador de reações de oxidação. Este efeito pode levar a danos celulares, com a perda pela exsudação de componentes de cor como a mioglobina, levando a alteração do parâmetro componente vermelho-verde $\left(\mathrm{a}^{*}\right)$, resultando, assim, uma carne menos avermelhada.

Os valores de $\mathrm{pH}$ inicial e final, perda de líquido no cozimento e perda de água por gotejamento (tabela VII) não apresentaram efeito de regressão de acordo com os níveis de fitase utilizados. Também não foram observadas diferenças entre os sexos e a interação entre os fatores ( $p>0,05)$. Porém, ao se comparar os resultados dos níveis de fitase com o grupo controle, o $\mathrm{pH}$ final foi afetado pelo nível de 500 UFA e a perda de líquido no descongelamento foi piorado pelo uso de 1500 UFA.

Segundo Edmonds e Arentson (2001), na fase de terminação a retirada de micro minerais e vitaminas da dieta não acarreta repercussões negativas na qualidade da carne ou efeitos significativos no $\mathrm{pH}$. Este resultado aponta que independente da fitase melhorar a disponibilidade de minerais e outros nutrientes, neste período final de engorda estas ações não são suficientes para promover as características qualita- tivas da carne.

Para o marmoreio, maciez e oxidação lipídica (tabela VIII) não foram observadas efeitos de regressão ou quaisquer diferenças entre os fatores ou a interação destes. Comparativamente ao grupo controle os tratamentos que receberam rações com fitase apresentaram-se semelhantes $(p>0,05)$ para estas variáveis.

Edmons e Arentson (2001) e Souza et al. (2008) mencionaram não haver diferenças na qualidade da carne, nos aspectos relacionados ao $\mathrm{pH}$, à cor, à firmeza e à força de cisalhamento de suínos alimentados com rações contendo ou não fitase.

Contrariando as observações de Gebert et al. (1999a, b), a inclusão de fitase não determinou piora na taxa de oxidação lipídica (TBARS), e para a dieta isenta de fitase, o ácido fítico presente nos ingredientes da

Tabela VIII. Medias e desvios-padrão observados para marmoreio (MARM), força de cisalhamento (FC), e oxidação lipídica (TBA) da carne de suínos, de acordo com o nível de inclusão de fitase na ração e do sexo. (Mean and standard deviation of marbling (MARM), shear force (FC) and lipids oxidation (TBA) of pork related to inclusion levels of phytase in the diet and to the pig sex).

\begin{tabular}{lccc}
\hline Tratamentos & MARM & $\begin{array}{c}\text { FC } \\
(\mathrm{kgf})\end{array}$ & $\begin{array}{c}\text { TBA } \\
(\mathrm{mg} / \mathrm{kg})\end{array}$ \\
\hline \multicolumn{3}{c}{ Níveis de fitase } \\
0 UFA & $1,56 \pm 0,2$ & $4,79 \pm 1,0$ & $0,16 \pm 0,02$ \\
500 UFA & $1,57 \pm 0,1$ & $4,81 \pm 1,2$ & $0,23 \pm 0,07$ \\
1000 UFA & $1,70 \pm 0,3$ & $4,70 \pm 1,4$ & $0,15 \pm 0,04$ \\
1500 UFA & $1,67 \pm 0,2$ & $4,34 \pm 0,8$ & $0,18 \pm 0,04$ \\
Sexos & & & \\
Macho & $1,66 \pm 0,2$ & $4,40 \pm 1,0$ & $0,17 \pm 0,05$ \\
Fêmea & $1,59 \pm 0,1$ & $4,92 \pm 1,1$ & $0,19 \pm 0,06$ \\
\multicolumn{5}{r}{} & $\mathrm{NS}$ & $\mathrm{NS}$ & $\mathrm{NS}$ \\
\hline CV1(\%) & 14,41 & 23,94 & 20,49 \\
Teste de Dunnnet & - & - & - \\
Regressão & - & - & - \\
\hline
\end{tabular}

CV: Coeficiente de variação. 


\section{FITASE PARA RAÇÕES COM ALTO ÁCIDO FÍTICO}

dieta, em especial no FGMD, diferente dos resultados obtidos por Harbach et al. (2006), não determinou melhora no índice de oxidação da carne.

\section{CONCLUSÕES}

A adição de fitase no nível de 1000 UFA,

\section{BIBLIOGRAFIA}

Almeida, R.F., Lopes, E.L., Nunes, R.C., Matos, M.P.C., Sobestiansky, J., Fioravanti, M.C.S., Oliveira, A.P.A. e Rufino, L.M. 2007. Metabolismo do ferro em suínos recebendo dietas contendo fitase, níveis reduzidos de fósforo inorgânico e sem suplemento micro mineral e vitamínico. Ciênc. Rural, 37: 1097-1103.

Beers, S. and Jongbloed, A.W. 1992. Apparent overall (total tract) digestibility of $\mathrm{P}$ in relation to doses of Aspergillus niger phytase in diets for pigs. J. Anim. Sci., 70: 242.

Biehl, R.R. and Baker, D.H. 1996. Efficacy of supplemental $1 \alpha$-hydroxicholecalciferol and microbial phytase for young pigs fed phosphorus or aminoacid-deficient corn-soybean meal diets. J. Anim. Sci., 74: 2960-2966.

Boccard, R., Buchter, L., Casteels, E., Cosentino, E., Dransfield, E., Hood, D.E., Joseph, R.L., MacDougall, D.B., Rhodes, D.N., Schon, I., Tinbergen, B.J. and Touraille,V. 1981. Procedures for measuring meat quality characteristics in beef production experiments. Report of a working group in the Comission of the European Communities beef production research programme. Liv. Prod. Sci., 8: 385-397.

Bouton, P.E., Harris, P.V and Shorthose, W.R. 1971. Effect of ultimate $\mathrm{pH}$ upon the waterholding capacity and tenderness of mutton. $J$. Food Sci., 36: 435-439.

Bridi, A.M. e Silva, C.A. 2007. Métodos de avaliação da carcaça e da carne suína. Midiograf. Londrina. $97 \mathrm{pp}$.

Chen, P.S., Toribara, T.Y. and Warner, H. 1956. Microdetermination of phosphorus. Anal. Chem., 28: 1756-1758.

Corassa, A., Lopes, D.C. e Teixeira, D.C. 2009. Ractopamina e fitase em dietas para suínos na fase de terminação. Rev. Bras. Zootecn., 38: 2174-2181. em dietas a base de ingredientes vegetais com alta concentração de ácido fítico, para suínos em fase terminação, é efetiva para promover a melhora da conversão alimentar, com a manutenção das características de carcaça e de qualidade de carne, determinando a redução do fósforo nas fezes, um aspecto positivo para a questão ambiental.

Crackel, R.L., Gray, I.J., Pearson, A.M., Booren, A.M. and Buckley, O.J. 1988. Some further observations on the TBA test as an index of lipid oxidation in meats. Food Chem., 28: 187-196.

Cromwell, G.L., Coffey, R.D., Parker, G.R., Monegus, H.J. and Randolf, J.H. 1995. Efficacy of low-ativity, microbial phytase in improving the biodisponibility of phosphorus in corn-soybean meal diets for pigs. J. Anim. Sci., 73: 449-456.

Edmonds, M.S. and Arentson, B.E. 2001. Effect of supplemental vitamins and trace mineral on performance and carcass quality in finishing pigs. J. Anim. Sci., 79: 141-147.

Figueirêdo, A.V., Fialho, E.T, Vitti, D.M.S.S., Lopes, J.B., Silva Filho, J.C., Teixeira, A.S. e Lima, J.A.F. 2000. Ação da fitase sobre a disponibilidade biológica do fósforo, por intermédio da técnica de diluição isotópica, em dietas com farelo de arroz integral para suíno. Rev. Bras. Zootecn., 29: 177-182.

Gebert, S., Bee, G., Pfirter, H.P. and Wenk, C. 1999a. Phytase and vitamin $E$ in the feed of growing pigs: I. Influence on growth, mineral digestibility and fatty acid in digest. J. Anim. Physiol. Anim. Nutr., 81: 9-19.

Gebert, S., Bee, G., Pfirter, H.P. and Wenk, C. 1999b. Phytase and vitamin $E$ in the feed of growing pigs: II. Influence on carcass characteristics, meat and fat quality. J. Anim. Physiol. Anim. Nutr., 81: 20-30.

Ghiretti, G.P., Zanardi, E., Novelli, E., Campanini, G., Dazzi, G., Madarena, G. and Chizzolini, R. 1997. Comparative evaluation of some antioxidants in salami milano and mortadella production. Meat Sci., 47: 167-176.

Graf, E. and Eaton, J.W. 1990. Antioxidant functions of phytic acid. Free Rad. Biol. Med., 8: 61-69.

Guidoni, A.L. 2000. Melhoria de processos para 


\section{LOZANO ETAL.}

tipificaçao e valorizaçao de carcaças suínas no Brasil. Em: Conferencia Internacional Virtual sobre a Qualidade de Carne Suína. Anais... EMBRAPA-CNPSA. Concórdia. pp: 221-234.

Harbach, A.P.R., Costa, M.C.R, Soares, A.L., Bridi, A.M., Shimokomaki, M. Silva, C.A. and Ida, E.I 2006. Dietary corn germ containing phytic acid prevents pork meat lipid oxidation while maintaining normal animal growth performance. Food Chem., 100: 1630-1633.

Harper, A.F., Kornegay, E.T. and Schell, T.C. 1997. Phytase supplementation of low-phosphorus growing-finishing pig diets improves performance phosphorus digestibility and bone mineralization and reduces phosphorus excretion. J. Anim. Sci., 75: 3174-3186.

Liu, J., Bollinger, D.W., Ledoux, D.R., Ellersieck, M. R. and Veum, T. L. 1997. Soaking increases the efficacy of supplemental microbial phytase in a low-phosphorus corn-soybean meal diet for growing pigs. J. Anim. Sci., 75: 1292-1298.

Ludke, M.C.M.M., López, J., Ludke, J.V. e Nicolaiewsky, S. 2002a. Utilização da fitase em dietas com ou sem farelo de arroz desengordurado para suínos em crescimento/ terminação. Rev. Bras. Zootecn., 31: 20022010.

Ludke, M.C.M.M., López, J. e Ludke, J.V. 2002b. Fitase em dietas para suínos em crescimento. I. Impacto ambiental. Ciênc. Rural, 32: 97-102.

Ludke, M.C.M.M., López, J. e Ludke, J.V. 2002c. Fitase em dietas para suínos em crescimento. II. Parâmetros de carcaça e ossos. Ciênc. Rural, 32: 103-108.

Malavolta, E., Vitti, G.C. e Oliveira, S.A. 1992. Avaliação do estado nutricional das plantas: princípios e aplicação. $2^{a}$ ed. Potafós. São Paulo. 234 pp.

Moreira, J.A., Vitti, D.M.S.S., Trindade Neto, M.A. and Lopes, J.B. 2003. Phytase enzyme in diets containing defatted rice brand for growing swine. Sci. Agric., 60: 631-636.

Moreira, J.A., Vitti, D.M.S.S., Lopes, J.B. e Trindade Neto, M.A. 2004. Fluxo biológico do fósforo no metabolismo de suínos alimentados com dietas contendo fitase. Rev. Bras. Zootecn., 33: 20662075.

Mroz, Z., Jongbloed, A.W. and Kemme, P.A. 1994. Apparent digestibility and retention of nutrients bound to phytate complexes as influenced by microbial phytase and feeding regimen in pigs. J. Anim. Sci., 72: 126-132.

National Pork Producers Council. 1991. Procedures to evaluate market. $3^{a}$ ed. Des Moines. lowa.

NRC. 1998. Nutritional requirements of swine. $10^{\text {th }}$ ed. National Research Council. National Academy Press. Washington. 189 pp.

Peter, C.M., Parr, T.M, Webel, D.M and Baker, D.H. 2001. The effects of phytase on growth performance, carcass characteristics, and bone mineralization of late-finishing pigs fed maizesoyaben meal diets containing no supplemental phosphorus, zinc, cooper and manganese. Anim. Feed Sci. Technol., 94: 199-205.

Pointillart, A. 1991. Enhancement of phosphorus utilization in growing pigs fed phytase-rich diets by using rye bran. J. Anim. Sci., 69: 1109-1115.

Sampaio, I.B.M. 1998. Estatística aplicada à experimentação animal. Universidade Federal de Minas Gerais. Belo Horizonte-MG. 221 pp.

Santos, S.P., Nunes, R.C., Lopes, E.L., Roner, M.N.B., Stringhini, J.H., Oliveira, A.P.A. e Rufino, L. M. 2008. Retirada do suplemento micro mineral, redução de fósforo inorgânico e adição de fitase em rações de suínos na fase de terminação. Ciênc. Anim. Bras., 9: 663-671.

Silva, F.C. 1999. Manual de análises químicas de solo, plantas e fertilizantes. EMBRAPA. Brasília. $370 \mathrm{pp}$.

Souza,C.M., Nunes, R.C., Matos, M.P.C., Coelho, K.O., Mesquita, A.J. e Nunes, I.A. 2008. Efeito da remoção de suplementos microminerais e vitamínicos, associada a redução do fósforo e adição da fitase sobre a vida de prateleira da carne suína refrigerada. Cienc. Anim. Bras., 9: 746-752.

Tarladgis, B.G., Pearson, A.M and Dugan Jr., L.R. 1964. Chemistry of the 2-thiobarbituric test for determination of oxidative rancidity in foods. II. Formation of the TBA-malonaldehyde complex without acid-heat treatment. J. Food Sci. Agric., 5: 602-604.

Thompson, D.B. and Erdman, J.W. 1982. Phytic acid determination in soybeans. J. Food Sci., 47: 513-517.

UFV. 1997. SAEG-Sistema de análises estatísticas e genéticas. Versão 7.1. Universidade Federal de Viçosa. Viçosa, MG. 150 pp. 